\title{
Preparation of Metal Complexes of 4,5-Dichlorphthalic Acid as Nanoscale and Electronic Properties
}

\author{
Mehmet Salih KESKIN ${ }^{1}$, Ümit YILDIKO², Derya GÜNGÖRDÜ SOLĞUN ${ }^{3}$, Mehmet Salih AĞIRTAŞ ${ }^{3 *}$
}

\begin{abstract}
Here phthalic acid metal complexes with acid function were synthesized. Fourie transform infrared spectroscopy (FT- IR), X-ray diffraction analysis (XRD), Scanning electron microscopy-Energy Dispersive Spectrometry (SEM+EDS) devices were used for structure analysis. The structural parameters of the copper and zinc complexes of 4,5-dichlorphthalic acid were determined by the LanL2DZ basis base set of B3LYP method. Electronic properties such as HOMO (highest occupied molecular orbital) and LUMO (lowest unoccupied molecular orbital) energies and molecular electrostatic potential (MEP) were obtained. Stability, charge delocalization of molecules resulting from hyperconjugative interactions were analyzed using natural bond orbital (NBO) analysis. The comparison of the theoretical and experimental FT-IR spectra of $\mathrm{Zn}$ and $\mathrm{Cu}-4,5$-dichlorphthalic acid (DCPA) were made and $\mathrm{R}=0.97204$ for $\mathrm{Cu}$ and $\mathrm{R}=0.97929$ for $\mathrm{Zn}$ complex were found in linear fit studies. Two characterization results were found to be consistent.
\end{abstract}

Key words: Phthalic acid derivative, synthesis, metal, electronic properties.

\section{Nano-Ölçekli Olarak 4,5-Diklorftalik Asit Metal Komplekslerinin Hazırlanması ve Elektronik Özellikler}

ÖZET: Burada asit fonksiyonlu ftalik asit metal kompleksleri sentezlendi. Yapı analizi için Fourie dönüşümü kızılötesi spektroskopisi (FT-IR), X-ışını kırınım analizi (XRD), Taramalı elektron mikroskopisi-Enerji Dağıtıcı Spektrometresi (SEM + EDS) cihazları kullanılmıştır. 4,5-diklorftalik asidin bakır ve çinko komplekslerinin yapısal parametreleri, B3LYP yönteminin LanL2DZ baz seti ile belirlenmiştir. HOMO (en yüksek işgal edilen moleküler orbital) ve LUMO (en düşük işgal edilmeyen moleküler orbital) enerjileri ve elektron yoğunluk dağılım potansiyeli (MEP) gibi elektronik özellikler elde edildi. Hiperkonjugatif etkileşimlerden kaynaklanan moleküllerin stabilitesi, yük delokalizasyonu, doğal bağ orbital (NBO) analizi kullanılarak analiz edildi. Zn ve $\mathrm{Cu}$-4,5-diklorftalik asidin (DCPA) teorik ve deneysel FT-IR spektrumlarının karşılaştırılması yapıldı ve $\mathrm{Cu}$ için $\mathrm{R}=0.97204$ ve $\mathrm{Zn}$ kompleksi için $\mathrm{R}=0.97929$ doğrusal çalışmalar formunda bulundu. İki karakterizasyon sonucunun tutarlı olduğu bulunmuştur.

Anahtar Kelimeler: Ftalik asit türevi, sentez, metal, elektronik özellikler

${ }^{1}$ Mehmet Salih KESKIN (Orcid ID: 0000-0001-9862-1590), Siirt Üniversitesi, Eğitim Fakültesi, Bilim Bölümü, Siirt, Türkiye

${ }^{2}$ Ümit YILDIKO (Orcid ID: 0000-0001-8627-9038), Kafkas Üniversitesi, Mühendislik-Mimarlık Fakültesi, Biyomühendislik Bölümü, Kars, Türkiye

${ }^{3}$ Derya GÜNGÖRDÜ SOLĞUN (Orcid ID:0000-0001-9492-5669), Mehmet Salih AĞIRTAŞ (Orcid ID: 0000-00031296-2066), Van Yüzüncü Y1l Üniversitesi, Bilim Fakültesi, Kimya Bölümü, Van, Türkiye

*Sorumlu Yazar/Corresponding Author: Mehmet Salih AĞIRTAŞ, e-mail: salihagirtas@hotmail.com 


\section{INTRODUCTION}

Phthalic acid and its derivatives are industrially needed chemical compounds. This compound and its derivatives are used in many fields such as paint, detergent, photocatalytic, cosmetic (Liu L.-C. et al., 2014). Due to technological developments and increasing world population, the new chemical demand has also increased. The use of phthalic acid derivatives in the reduction of toxic pollutants such as $\mathrm{Cr}$ (VI) by modifying them on the $\mathrm{TiO}_{2}$ surface is of interest for research (Liu H. et al., 2011). In this study, it is considered that especially prepared compounds can be used as support materials. There are studies based on phthalic acid supported synthesis of silver nanoparticles. It is used for sensor studies. However, similar copper and zinc nanoparticles are not found in the literature. Zinc and copper-containing phthalic acid derivatives may also be used as sensors or catalyst support (Detsri and Seeharaj, 2017). The theoretical chemical calculations of DFT B3LYP have been studied well and consistently (Cabir et al., 2020; Prabhaharan et al., 2015; Priya et al., 2019; Rocha et al., 2015). Theoretical studies have been used in many studies on organo metal compounds (El Bourakadi et al., 2019; Kumar et al., 2019; Pandey et al., 2017; Solğun et al., 2020). It is also important to understand the behavior of the more dense phases of the complexes (Cabir et al., 2019; Jayaprakash et al., 2011; Mihçıkur and Özpozan, 2017). 4,5dichlorphthalic acid and its complexes have been the most frequent subject of experimental research due to their importance in the industry. To the best of our knowledge, literature review has shown that there are no their DFT studies.

In this study, structural analyzes were calculated theoretically. Molecular geometry optimized structural parameters and HOMO - LUMO band gap, MEP and NBO analyzes were calculated by B3LYP method. Local and global chemical reactivity descriptors were calculated. The comparison of the theoretical and experimental FT-IR spectra of $\mathrm{Zn}$ and $\mathrm{Cu}$-DCPA were made and the results of the two characterizations were found to be consistent.

\section{EXPERIMENTAL AND THEORETICAL SECTION}

\section{Preparation of the copper complex (1)}

$0.227 \mathrm{~g}$ of 4,5-dichlorphthalic acid was dissolved in $10 \mathrm{ml}$ of ethanol. Then $0.200 \mathrm{~g}$ of $\mathrm{NaOH}$ was added to the medium and stirred. To this mixture was added $0.190 \mathrm{~g}$ of $\mathrm{CuCl}_{2}$ dissolved in $15 \mathrm{ml}$ of ethanol. The green solution turned to light green and began to precipitate. Stirring was continued at room temperature for 2 hours. The reaction was then stopped and filtered. Washed with ethanol. It was dried at $40^{\circ} \mathrm{C}$. Yield: $0.575 \mathrm{~g}$. EN $>320^{\circ} \mathrm{C}$. IR spectrum $\left(\mathrm{cm}^{-1}\right)$ : $1612,1544,1400,1323,1170,1128,1005$, 920, 900, 844, 808, 617.

\section{Preparation of the zinc complex (2)}

$0.227 \mathrm{~g}$ of 4,5-dichlorphthalic acid was dissolved in $10 \mathrm{ml}$ of ethanol. Then $0.200 \mathrm{~g}$ of $\mathrm{NaOH}$ was added to the medium and stirred. To this mixture was added $0.190 \mathrm{~g}$ of $\mathrm{ZnCl}_{2}$ dissolved in $15 \mathrm{ml}$ of ethanol. The white solution began to precipitate. Stirring was continued at room temperature for 2 hours. The reaction was then stopped and filtered. It was washed with ethanol. It was dried at $40{ }^{\circ} \mathrm{C}$. Yield: 0.487 g. EN $>320^{\circ} \mathrm{C}$. IR spectrum $\left(\mathrm{cm}^{-1}\right): 1612,1544,1400,1398,1323,1170,1128,1003,920,900$, $844,808,617$.

\section{Computational Study}

The potential energy profile of the compound was determined using the B3LYP / LanL2DZ method to find stable optimization. Theoretical calculations were made with the Gaussian-09 package program(M. J. Frisch, 2016), which promotes geometry optimization of B3LYP correlation 
functionality. The resulting stable conformers were further optimized using LanL2DZ basis sets. Thermodynamic properties and energy of the compound were determined using optimized geometry.

\section{RESULTS AND DISCUSSION}

Phthalic acid derivatives are chemical compounds needed in the chemical industry. Especially these derivatives can be used in many fields such as detergent, paint, photocatalytic, cosmetics. Technological advances and increased comfort, new chemical demand has also increased. Bringing phthalic acid derivatives to nanoscale may also allow the application of new functional properties. Metal complexes modified with DCPA (4,5-dichlorphthalic acid) are synthesized in Figure 1. DCPA is an aromatic-carboxylic acid capable of resonating only a pair of electrons on carbonyl and oxygen. As is known, the carboxylate moiety (-COO) is a common and popular functional group for the stabilization of NPs (Henglein and Giersig, 1999; Rawat et al., 2017).<smiles>O=C(O)c1cc(Cl)c(Cl)cc1C(=O)O</smiles>
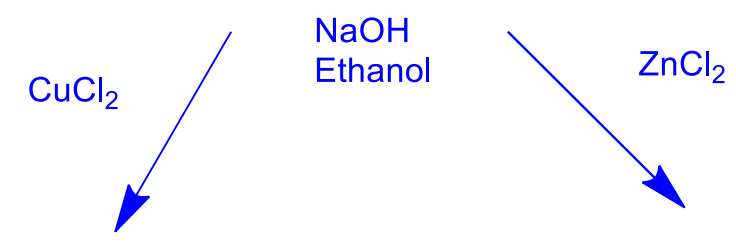<smiles>O=C1O[Ge](Cl)(Cl)OC(=O)c2cc(Cl)c(Cl)cc21</smiles>

1<smiles>O=C1O[Te](Cl)(Cl)OC(=O)c2cc(Cl)c(Cl)cc21</smiles>

2

Figure 1. Synthesis of metal complexes

The size and particle morphology of $\mathrm{Zn}$ and $\mathrm{Cu}$ complexes of DCPA were examined using SEM + EDS analysis (Figure 2,3). These images show that the compounds have reached nano dimensions. These data show that the compounds can be used to form active catalysts on surfaces.
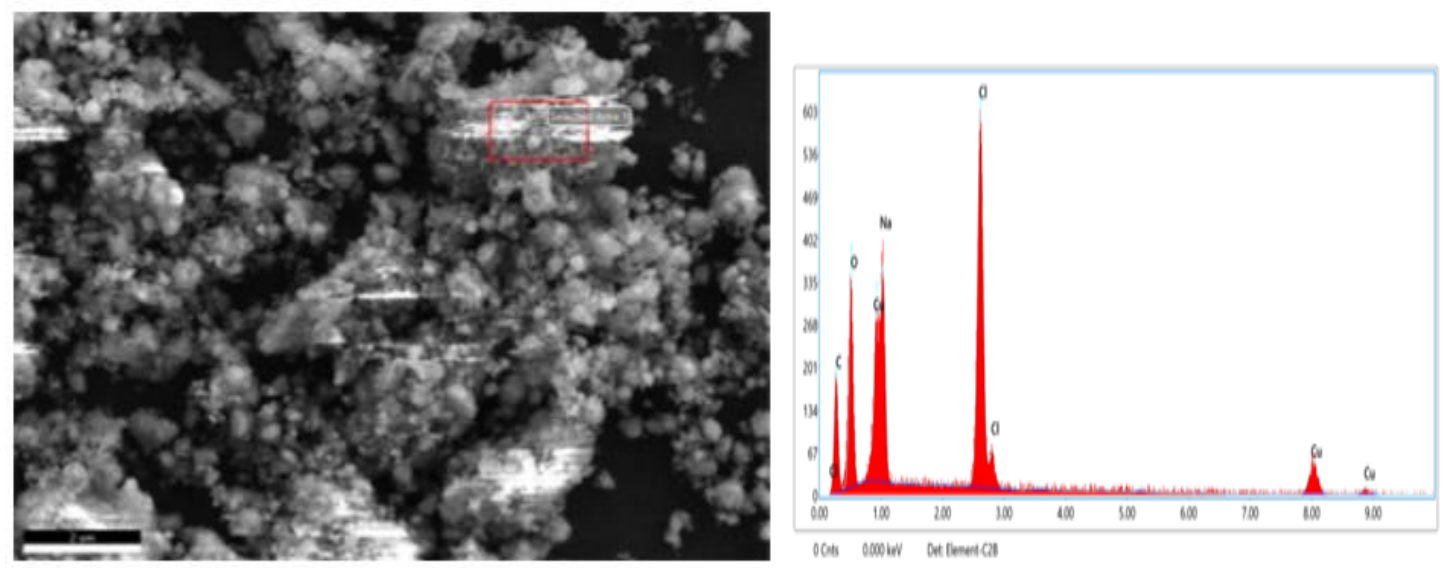

Figure 2. SEM image of the copper complex with EDS 

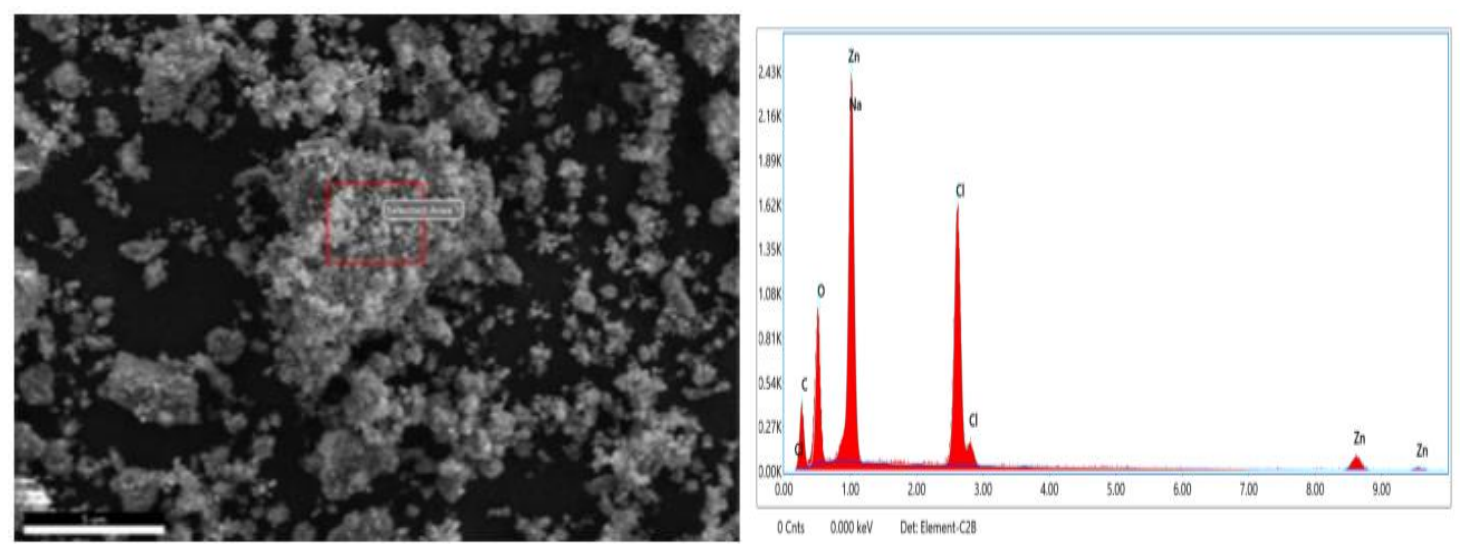

Figure 3. SEM image of the zinc complex with EDS

$\mathrm{X}$-ray diffractometer (XRD) was used to analyze the crystallographic structure of the $\mathrm{Zn}$ and $\mathrm{Cu}$ complexes of DCPA. XRD diagrams of these compounds are given in Figure 4. XRD patterns also confirm the structure.
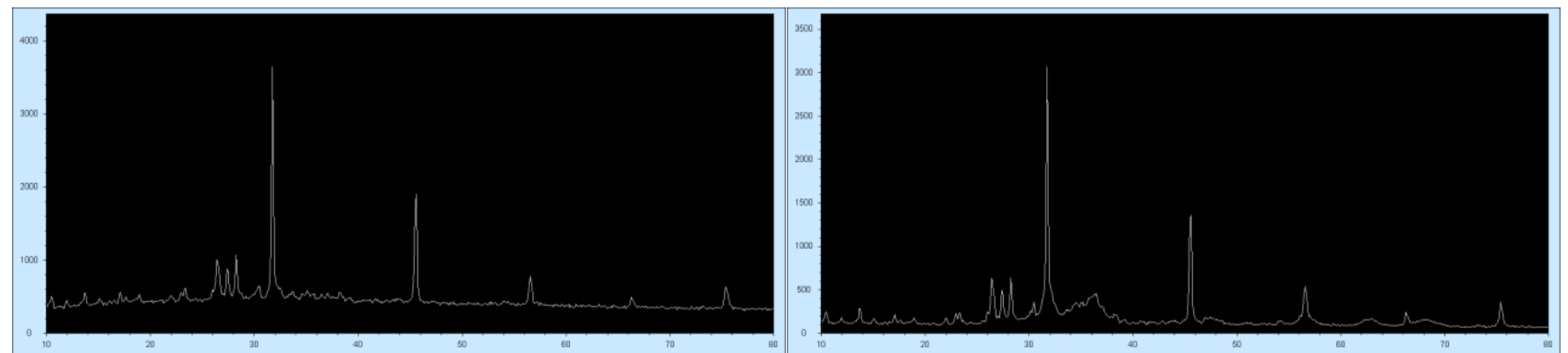

Figure 4. XRD patterns of the compound 2 (left)and 1(right)

\section{Molecular Geometry}

The most stable geometry of the compounds was optimized by the B3LYP method using higher level basis sets such as LanL2DZ The optimized geometry of the $\mathrm{Cu}$ and $\mathrm{Zn}$ compounds is shown in Figure 5. $\mathrm{Cu}-\mathrm{Cl}$ groups in $\mathrm{Cu}-4,5$-dichloro phthalic acid groups were in the range of $\mathrm{Cu} 19-\mathrm{C} 172.334 \AA$ for the DFT method, and Zn17-C118 2.450 $\AA$ for Zn-4,5-dichloro phthalic acid. In both complexes, bonding distance of $\mathrm{O}$ atom to metal atoms was found very close. When the bond angles $\mathrm{O}-\mathrm{Cu}-\mathrm{Cl}$ were examined, it was found 111.76 and $\mathrm{O}-\mathrm{Zn}-\mathrm{Cl} 131.16$.
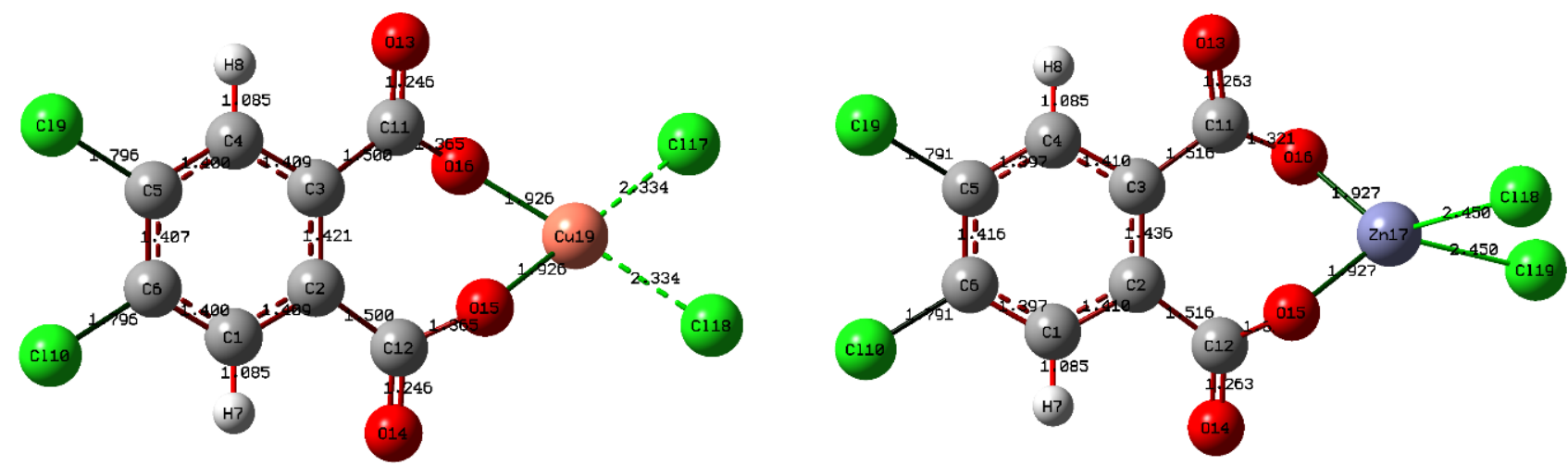

Figure 5. Optimized geometry of 4,5-dichlorphthalic acid complexes 


\section{Frontier Molecular Orbitals [HOMO-LUMO]}

Both HOMO and LUMO are the main orbitals involved in chemical stability (Demir and Akman, 2017; Prabhaharan et al., 2015; Srivastava et al., 2015). HOMO represents the ability to give an electron and LUMO represents the ability to become an electron acceptor. The four important molecular orbitals (MOs) for complex molecules are HOMO, LUMO and, the highest and second highest filled orbital (HOMO -1) and the lowest and lowest second empty orbital( LUMO + 1), respectively (Demir and Akman, 2017; Khajehzadeh and Moghadam, 2017; Prabhaharan et al., 2015; Rocha et al., 2015; Srivastava et al., 2015). These orbital energies were calculated by the B3LYP / LanL2DZ method and the figures are shown in Figure 6.

Table 1. Comparison of HOMO, LUMO, energy gaps (HOMO - LUMO) and related Zn and Cu complex DCPA molecular properties

\begin{tabular}{lcc}
\hline Molecules Energy & Cu- DCPA & Zn- DCPA \\
\hline ELUMO $_{\text {EHOMO }}$ & -6.4753 & -7.5679 \\
Energy Gap $(\Delta)$ EHOMO- ELUMO & -8.2389 & -8.0917 \\
Ionization Potential $\left(\mathrm{I}=-\mathrm{E}_{\mathrm{HOMO}}\right)$ & 1.7636 & 0.5238 \\
Electron Affinity $\left(A=-E_{\mathrm{LUMO}}\right)$ & 8.2389 & 8.0917 \\
Chemical hardness $(\eta=(I-A) / 2)$ & 6.4753 & 7.5679 \\
Chemical softness $(s=1 / 2 \eta)$ & 0.8818 & 0.2619 \\
Chemical Potential $(\mu=(I+A) / 2)$ & 0.4409 & 0.1309 \\
Electronegativity $(\chi=(1+A) / 2)$ & -7.3571 & -7.8298 \\
Electrophilicity index $\left(\omega=\mu^{2} / 2 \eta\right)$ & 3.7376 & -3.2839 \\
\hline
\end{tabular}

According to the calculated band gap, the large LUMO - HOMO value shows a hard molecule and the small LUMO - HOMO value shows a soft molecule structure. The chemical stability of the synthesized molecules also depends on the hardness, the decrease in bandwidth will make the molecule even more reactive. Frontier molecular orbitals calculations lead to show the reactivity and kinetic stability of the molecule. The LUMO - HOMO energy difference of DCPA was calculated in B3LYP / LanL2DZ. The HOMO energy of the $\mathrm{Cu}$ complex compound is $-8.2389 \mathrm{eV}$ and the LUMO energy is $6.4753 \mathrm{eV}$. The energy difference between LUMO and HOMO was $1.7636 \mathrm{eV}$. The HOMO energy of the $\mathrm{Zn}$ complex compound is $-8.0917 \mathrm{eV}$ and the LUMO energy is $-7.5679 \mathrm{eV}$. The energy difference between LUMO and HOMO was $0.5238 \mathrm{eV}$. The $\mathrm{Zn}$ complex is more reactive than the $\mathrm{Cu}$ complex.

\section{Vibration Analysis}

FT-IR spectra of Zn and Cu complex DCPA were obtained by DFT method using LANDL2DZ basis set. The theoretical and experimental FT-IR spectra of $\mathrm{Zn}$ and $\mathrm{Cu}-\mathrm{DCPA}$ were compared. $\mathrm{R}=$ 0.97204 for $\mathrm{Cu}$ and $\mathrm{R}=0.97929$ for $\mathrm{Zn}$ complex were found in linear fit studies. Two characterization results were found to be consistent. Comparison of the theoretical and experimental FT-IR frequencies are shown in Figure 7,8. 

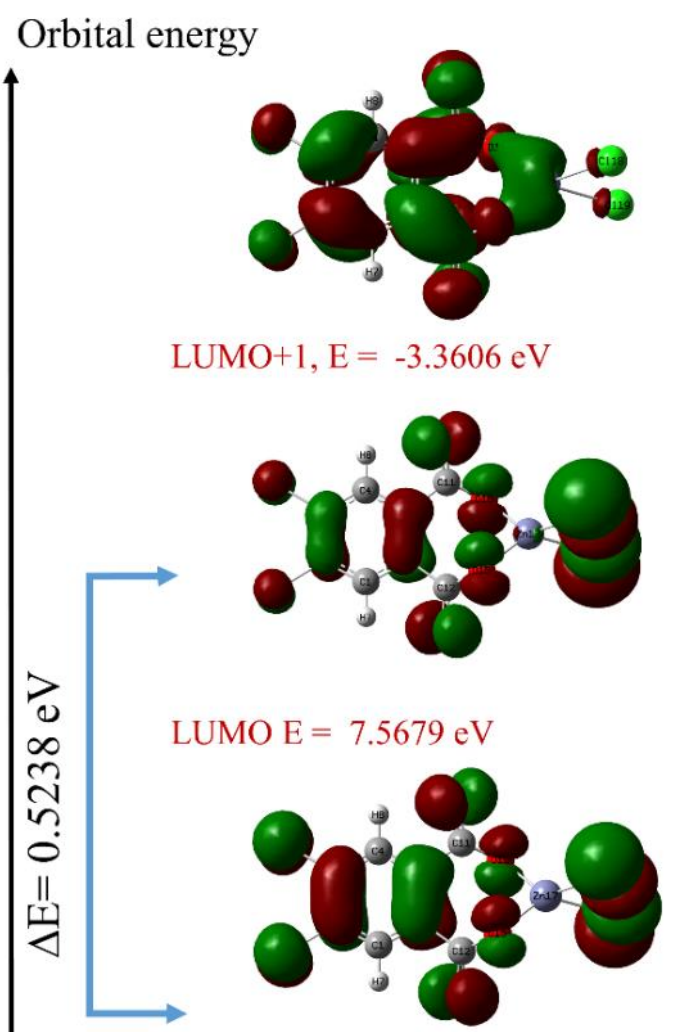

HOMO E $=-8.0917 \mathrm{eV}$

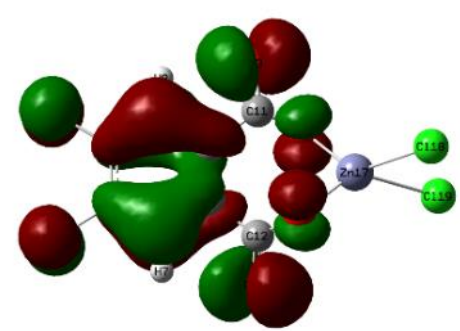

HOMO-1 $\mathrm{E}=-8.3785 \mathrm{eV}$

(a)

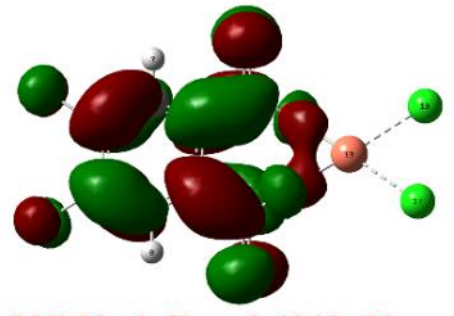

$\mathrm{LUMO}+1, \mathrm{E}=-3.4948 \mathrm{eV}$

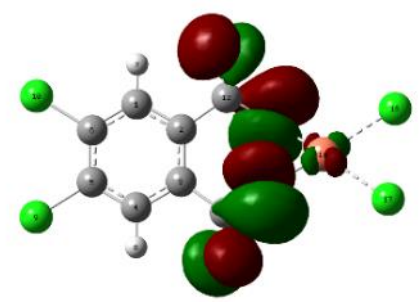

LUMO E $=--6.4753 \mathrm{eV}$

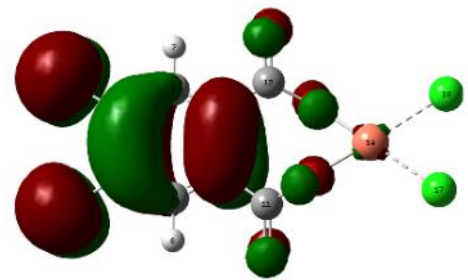

HOMO E $=-8.2389 \mathrm{eV}$

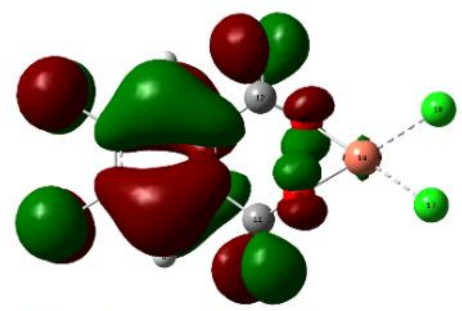

HOMO-1 E= $=-8.4466 \mathrm{eV}$

(b)

Figure 6. Frontier molecular orbitals of $\mathrm{Zn}$ (a) and $\mathrm{Cu}$ (b) complexes of 4,5-dichlorphthalic acid
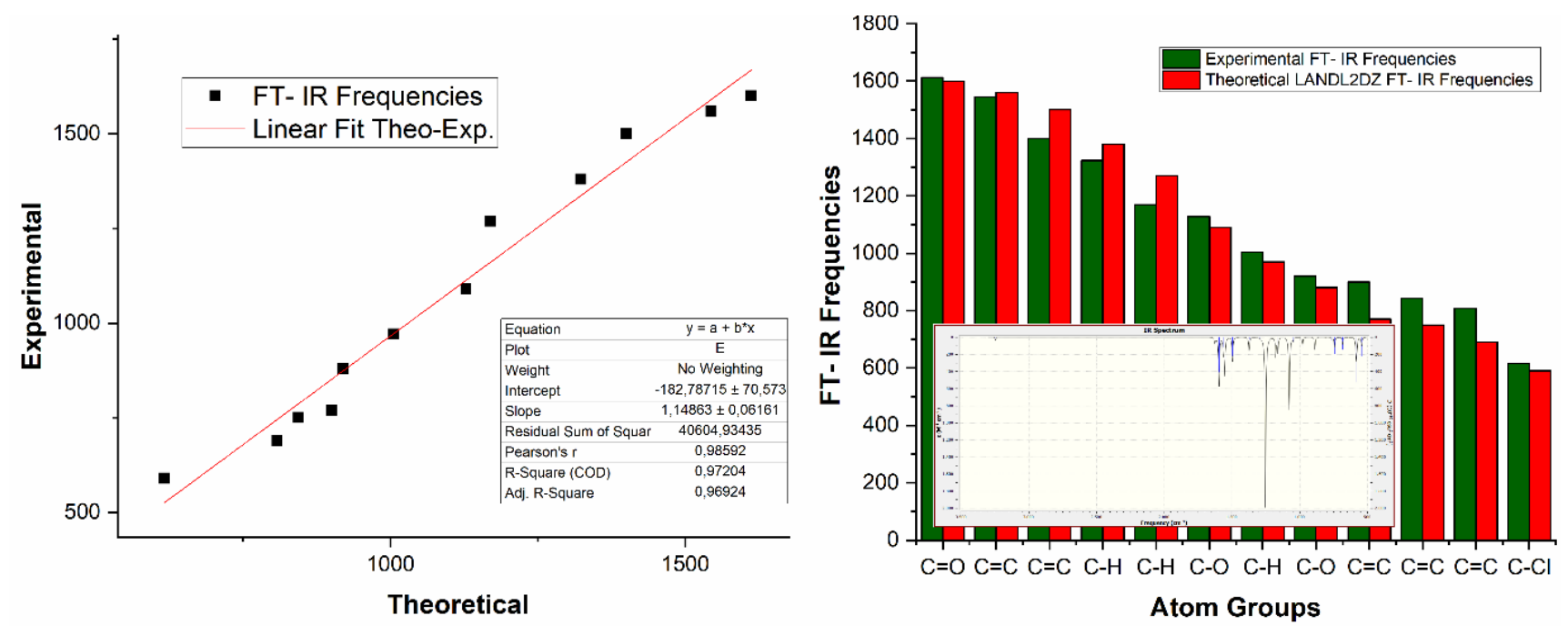

Figure 7. Comparison of theoretical and experimental FT-IR spectrum of $\mathrm{Cu}$ - DCPA 

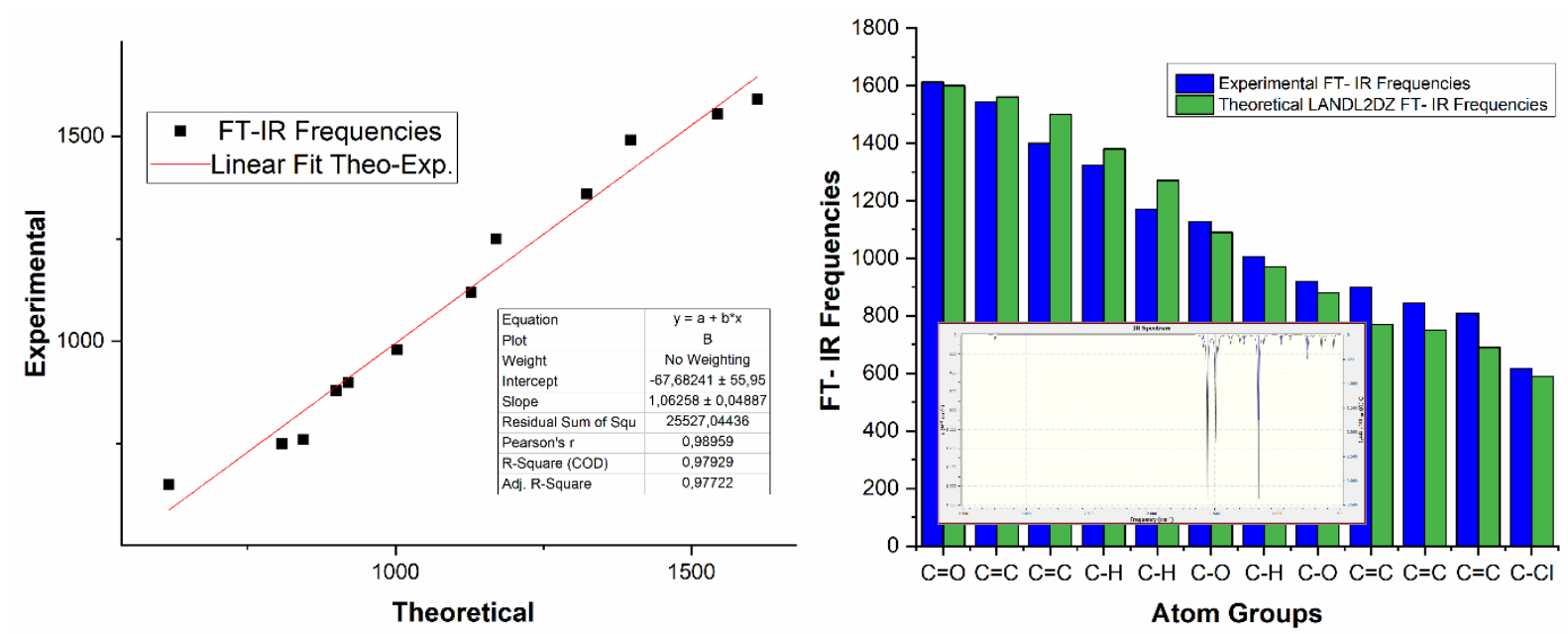

Figure 8. Comparison of theoretical and experimental FT-IR spectrum of Zn- DCPA

\section{Molecular Electrostatic Potential (MEP)}

In this study, molecular electrostatic potential (MEP) maps were obtained for both complexes. As shown in Figure 9, MEP maps of the Compound were mapped with the basis set LanL2DZ. It shows that the central atom has positive region regions characterized by the blue color around it. The contour map of the compounds verifies the negative and positive regions in accordance with the electrostatic surface potential (ESP) (Jayaprakash et al., 2011; Khajehzadeh and Moghadam, 2017; Saravanan et al., 2014; Srivastava et al., 2015; Vennila et al., 2016).
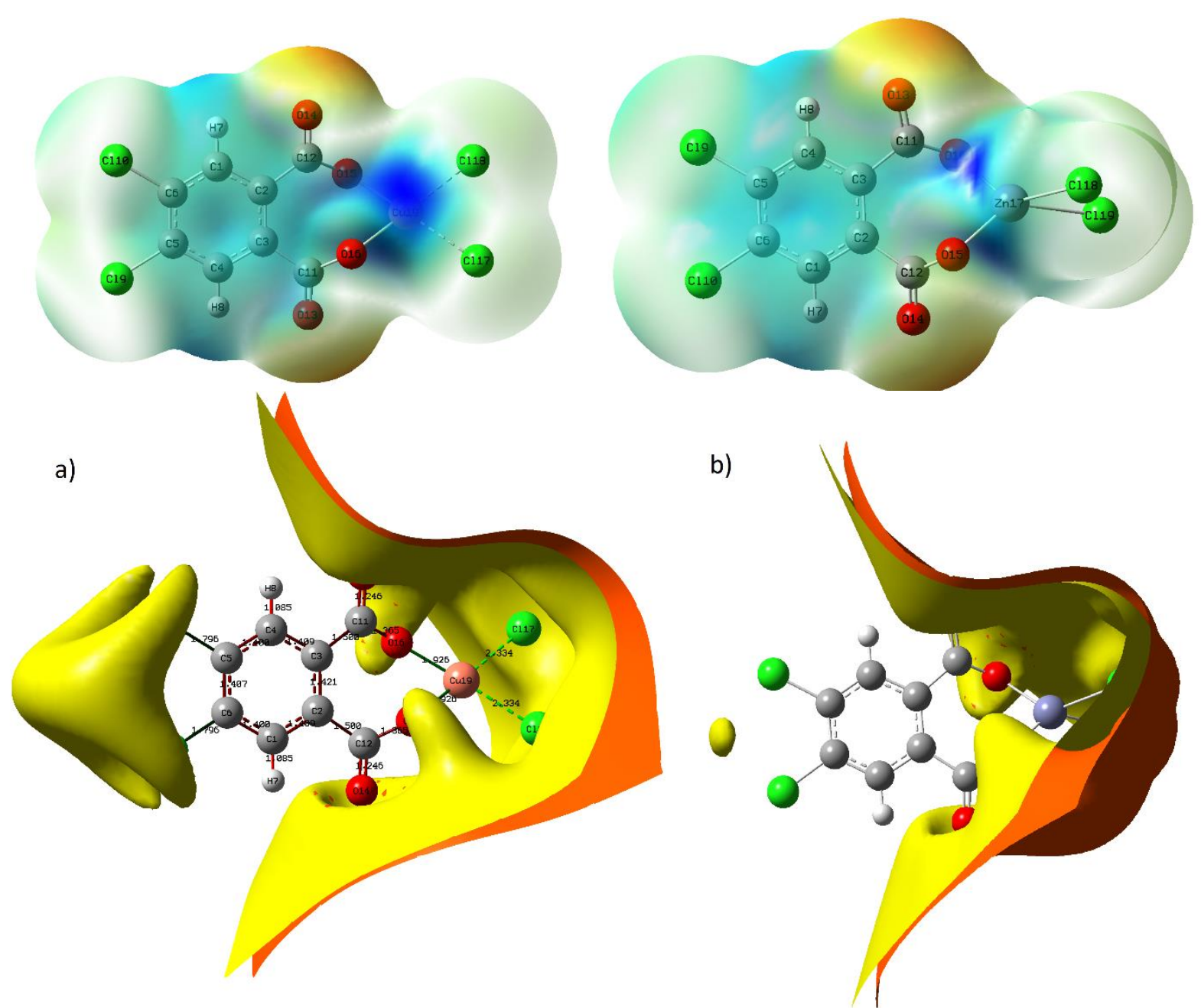

Figure 9. Molecular surface maps of $\mathrm{Cu}$ and $\mathrm{Zn}$ complex DCPA compounds 


\section{Natural Bond Orbital (NBO) Analysis}

The total stabilization energies of C1-C2 (occ. 0.79811)- C3-C4 (occ. 0.16115) $\sigma \rightarrow \sigma^{*}$ is 9.83 $\mathrm{kcal} \mathrm{mol}^{-1}$ and C12-O15 (occ. 1.98331) - Zn17-Cl18 (occ. 0.16881) $\sigma \rightarrow \sigma^{*} 0.23 \mathrm{kcal} \mathrm{mol}^{-1}$ were calculated. C5-C6 (occ. 0.77158) and C1-C2 (occ. 0.14989) between $\pi \rightarrow \pi * 9.98 \mathrm{kcalmol}^{-1}$. CR1-Cu19 (occ. 0.99921) and C11-O16 (occ. 0.05184) were calculated as $\sigma \rightarrow \sigma * 0.99 \mathrm{kcal} \mathrm{mol}^{-1}$. Between C5C6 (occ. 0.77158) and C1-C2 (occ. 0.14989) $\pi \rightarrow \pi^{*} 9.98 \mathrm{kcal} \mathrm{mol}^{-1}, \mathrm{CR} 1-\mathrm{Cu} 19$ (occ. 0.99921) and $\mathrm{C} 11-\mathrm{O} 16$ (occ. 0.05184 ) $\sigma \rightarrow \sigma^{*} 0.99 \mathrm{kcal} \mathrm{mol}^{-1}$ were calculated. The high values of $\mathrm{E}^{(2)}$ stabilization energies from the NBO analysis of the metalo complex compounds indicate the stability and $\pi$-electrons delocalization of the molecules (Eşme and Sağdınç, 2017; Khajehzadeh and Moghadam, 2017; Mathammal et al., 2015; Pandey et al., 2017). The natural electron configuration of $\mathrm{Zn}-\mathrm{Cu}$ complex compounds DCPA was calculated as $\mathrm{Cu} 19=[$ core $] 4 \mathrm{~s}^{(0.18)} 3 \mathrm{~d}^{(4.40)} 4 \mathrm{p}^{(0.33)}$ and $\mathrm{Zn} 17=[$ core $] 4 \mathrm{~s}^{(0.35)} 3 \mathrm{~d}^{(}$ 9.97) $4 \mathrm{p}^{(0.56)} 5 \mathrm{p}^{(0.01)}$. The results analyzed are given in Table 2,3 .

Table 2. Selected NBO results of $\mathrm{Cu}$ - complex compounds DCPA

\begin{tabular}{|c|c|c|c|c|c|c|c|c|}
\hline NBO(i) & Type & ED/e & $\mathbf{N B O}(\mathbf{j})$ & Type & ED//e & $\mathbf{E}(2)^{\mathrm{a}}(\mathrm{Kcal} / \mathrm{mol})$ & $\mathbf{E}(\mathbf{j})-\mathbf{E}(\mathbf{i})^{\mathbf{b}}$ (a.u.) & $\mathbf{F}(\mathbf{i}, \mathbf{j})^{\mathbf{c}}(\mathbf{a . u})$ \\
\hline \multirow[t]{6}{*}{$\mathrm{C} 1-\mathrm{C} 2$} & \multirow[t]{4}{*}{$\sigma$} & \multirow[t]{4}{*}{0.98195} & C1-C6 & $\sigma^{*}$ & 0.01424 & 1.09 & 1.24 & 0.047 \\
\hline & & & $\mathrm{C} 1-\mathrm{H} 7$ & $\sigma^{*}$ & 0.00753 & 0.58 & 1.25 & 0.034 \\
\hline & & & C6-Cl10 & $\sigma^{*}$ & 0.01668 & 2.35 & 0.89 & 0.058 \\
\hline & & & $\mathrm{C} 12-\mathrm{O} 15$ & $\sigma^{*}$ & 0.04486 & 1.06 & 0.94 & 0.041 \\
\hline & \multirow[t]{2}{*}{$\pi$} & \multirow[t]{2}{*}{0.79811} & $\mathrm{C} 3-\mathrm{C} 4$ & $\pi^{*}$ & 0.16115 & 9.83 & 0.29 & 0.068 \\
\hline & & & C12-O14 & $\pi^{*}$ & 0.11460 & 7.59 & 0.24 & 0.056 \\
\hline \multirow[t]{3}{*}{ C1-C6 } & \multirow[t]{3}{*}{$\sigma$} & \multirow[t]{3}{*}{0.98670} & $\mathrm{C} 1-\mathrm{H} 7$ & $\sigma^{*}$ & 0.00753 & 0.66 & 1.26 & 0.036 \\
\hline & & & $\mathrm{C} 2-\mathrm{C} 12$ & $\sigma^{*}$ & 0.03817 & 1.96 & 1.06 & 0.058 \\
\hline & & & $\mathrm{C} 5-\mathrm{Cl} 9$ & $\sigma^{*}$ & 0.01668 & 2.37 & 0.91 & 0.059 \\
\hline \multirow[t]{3}{*}{$\mathrm{C} 1-\mathrm{H} 7$} & \multirow[t]{3}{*}{$\sigma$} & \multirow[t]{3}{*}{0.98438} & $\mathrm{C} 1-\mathrm{C} 2$ & $\sigma^{*}$ & 0.01080 & 0.40 & 1.05 & 0.026 \\
\hline & & & $\mathrm{C} 2-\mathrm{C} 3$ & $\sigma^{*}$ & 0.01439 & 2.98 & 1.05 & 0.024 \\
\hline & & & C6-C110 & $\sigma^{*}$ & 0.01661 & 0.33 & 0.70 & 0.019 \\
\hline \multirow[t]{4}{*}{$\mathrm{C} 5-\mathrm{C} 6$} & \multirow[t]{2}{*}{$\sigma$} & \multirow[t]{2}{*}{0.98670} & C1-C6 & $\sigma^{*}$ & 0.01425 & 1.22 & 1.29 & 0.050 \\
\hline & & & $\mathrm{C} 1-\mathrm{H} 7$ & $\sigma^{*}$ & 0.00746 & 1.24 & 1.30 & 0.051 \\
\hline & \multirow[t]{2}{*}{$\pi$} & \multirow[t]{2}{*}{0.77158} & $\mathrm{C} 1-\mathrm{C} 2$ & $\pi^{*}$ & 0.14989 & 9.98 & 0.32 & 0.072 \\
\hline & & & $\mathrm{C} 3-\mathrm{C} 4$ & $\pi^{*}$ & 0.14989 & 9.98 & 0.32 & 0.072 \\
\hline \multirow[t]{2}{*}{ C6-Cl10 } & \multirow[t]{2}{*}{$\sigma$} & \multirow[t]{2}{*}{0.99052} & $\mathrm{C} 1-\mathrm{C} 2$ & $\sigma^{*}$ & 0.01080 & 1.80 & 1.18 & 0.058 \\
\hline & & & $\mathrm{C} 4-\mathrm{C} 5$ & $\sigma^{*}$ & 0.01425 & 2.12 & 1.18 & 0.063 \\
\hline \multirow[t]{3}{*}{ C11-O13 } & $\sigma$ & 0.99551 & $\mathrm{C} 2-\mathrm{C} 3$ & $\sigma^{*}$ & 0.01439 & 0.90 & 1.53 & 0.047 \\
\hline & \multirow[t]{2}{*}{$\pi$} & \multirow[t]{2}{*}{0.92270} & $\mathrm{C} 2-\mathrm{C} 3$ & $\pi^{*}$ & 0.01439 & 0.31 & 0.90 & 0.021 \\
\hline & & & $\mathrm{C} 3-\mathrm{C} 4$ & $\pi^{*}$ & 0.14989 & 1.31 & 0.40 & 0.031 \\
\hline \multirow[t]{4}{*}{$\mathrm{CR} 1-\mathrm{C} 1$} & \multirow[t]{4}{*}{$\sigma$} & \multirow[t]{4}{*}{0.99946} & $\mathrm{C} 2-\mathrm{C} 3$ & $\sigma^{*}$ & 0.01439 & 0.46 & 10.60 & 0.089 \\
\hline & & & $\mathrm{C} 2-\mathrm{C} 12$ & $\sigma^{*}$ & 0.04043 & 0.36 & 10.41 & 0.079 \\
\hline & & & C5-C6 & $\sigma^{*}$ & 0.02421 & 0.51 & 10.61 & $0 . .094$ \\
\hline & & & C6-Cl10 & $\sigma^{*}$ & 0.01661 & 0.28 & 10.26 & 0.068 \\
\hline CR1-O14 & $\sigma$ & 0.99994 & $\mathrm{C} 2-\mathrm{C} 12$ & $\sigma^{*}$ & 0.04043 & 0.27 & 19.26 & 0.092 \\
\hline \multirow[t]{2}{*}{ CR1-Cu19 } & $\sigma$ & 0.99921 & C11-O16 & $\sigma^{*}$ & 0.05184 & 0.99 & 4.59 & 0.087 \\
\hline & & & C12-O15 & $\sigma^{*}$ & 0.05184 & 1.02 & 4.59 & 0.088 \\
\hline LP1-C110 & $\sigma$ & 0.99445 & C1-C6 & $\sigma^{*}$ & 0.01425 & 1.01 & 1.18 & 0.044 \\
\hline & & & C5-C6 & $\sigma^{*}$ & 0.02421 & 0.81 & 1.17 & 0.039 \\
\hline LP2-C110 & $\sigma$ & 0.98544 & $\mathrm{C} 1-\mathrm{C} 2$ & $\sigma^{*}$ & 0.01080 & 0.32 & 0.83 & 0.021 \\
\hline & & & C1-C6 & $\sigma^{*}$ & 0.01425 & 1.98 & 0.83 & 0.051 \\
\hline & & & $\mathrm{C} 4-\mathrm{C} 5$ & $\sigma^{*}$ & 0.01425 & 0.31 & 0.83 & 0.020 \\
\hline & & & C5-C6 & $\sigma^{*}$ & 0.02421 & 2.63 & 0.83 & 0.059 \\
\hline LP3-Cl10 & $\sigma$ & 0.93030 & C5-C6 & $\sigma^{*}$ & 0.02421 & 6.98 & 0.29 & 0.063 \\
\hline LP1-O16 & $\sigma$ & 0.95134 & $\mathrm{C} 3-\mathrm{C} 11$ & $\sigma^{*}$ & 0.04043 & 4.46 & 0.78 & 0.075 \\
\hline & & & C11-O13 & $\sigma^{*}$ & 0.01721 & 1.38 & 0.92 & 0.046 \\
\hline
\end{tabular}


Table 3. Selected NBO results of $\mathrm{Zn}$ - complex compounds DCPA

\begin{tabular}{|c|c|c|c|c|c|c|c|c|}
\hline NBO(i) & Type & ED/e & $\operatorname{NBO}(\mathbf{j})$ & Type & ED//e & $\mathrm{E}(2)^{\mathrm{a}}(\mathrm{Kcal} / \mathrm{mol})$ & $\mathbf{E}(\mathbf{j})-\mathbf{E}(\mathbf{i})^{\mathbf{b}}$ (a.u.) & $\mathbf{F}(\mathbf{i}, \mathbf{j})^{\mathbf{c}}(\mathbf{a} . \mathbf{u})$ \\
\hline \multirow[t]{4}{*}{$\mathrm{C} 1-\mathrm{C} 2$} & $\sigma$ & 1.96155 & C1-C6 & $\sigma^{*}$ & 0.02745 & 1.98 & 1.24 & 0.044 \\
\hline & & & $\mathrm{C} 1-\mathrm{H} 7$ & $\sigma^{*}$ & 0.01354 & 1.07 & 1.24 & 0.033 \\
\hline & & & C6-C110 & $\sigma^{*}$ & 0.03231 & 4.69 & 0.89 & 0.058 \\
\hline & & & $\mathrm{C} 12-\mathrm{O} 15$ & $\sigma^{*}$ & 0.06665 & 1.68 & 0.97 & 0.036 \\
\hline \multirow[t]{5}{*}{ C1-C6 } & $\sigma$ & 1.97280 & $\mathrm{C} 1-\mathrm{H} 7$ & $\sigma^{*}$ & 0.01354 & 1.26 & 1.26 & 0.036 \\
\hline & & & $\mathrm{C} 2-\mathrm{C} 12$ & $\sigma^{*}$ & 0.06646 & 4.57 & 1.06 & 0.063 \\
\hline & & & $\mathrm{C} 5-\mathrm{Cl} 9$ & $\sigma^{*}$ & 0.03231 & 4.62 & 0.91 & 0.058 \\
\hline & $\pi$ & 1.63987 & C1-C6 & $\pi^{*}$ & 0.34451 & 0.64 & 0.29 & 0.012 \\
\hline & & & $\mathrm{C} 4-\mathrm{C} 5$ & $\pi^{*}$ & 0.34451 & 20.94 & 0.29 & 0.070 \\
\hline \multirow[t]{3}{*}{$\mathrm{C} 1-\mathrm{H} 7$} & $\sigma$ & 1.97038 & $\mathrm{C} 1-\mathrm{C} 2$ & $\sigma^{*}$ & 0.02368 & 0.79 & 1.05 & 0.026 \\
\hline & & & $\mathrm{C} 2-\mathrm{C} 3$ & $\sigma^{*}$ & 0.03197 & 5.91 & 1.07 & 0.071 \\
\hline & & & C6-C110 & $\sigma^{*}$ & 0.03231 & 0.61 & 0.70 & 0.018 \\
\hline \multirow[t]{2}{*}{ C5-C6 } & $\sigma$ & 1.98369 & C1-C6 & $\sigma^{*}$ & 0.02745 & 2.31 & 1.28 & 0.049 \\
\hline & & & C1-H7 & $\sigma^{*}$ & 0.01354 & 2.49 & 1.29 & 0.051 \\
\hline \multirow[t]{2}{*}{ C6-Cl10 } & $\sigma$ & 1.98102 & $\mathrm{C} 1-\mathrm{C} 2$ & $\sigma^{*}$ & 0.02368 & 3.49 & 1.18 & 0.057 \\
\hline & & & $\mathrm{C} 4-\mathrm{C} 5$ & $\sigma^{*}$ & 0.02745 & 4.17 & 1.17 & 0.063 \\
\hline \multirow[t]{3}{*}{ C11-O13 } & $\sigma$ & 1.96013 & $\mathrm{C} 2-\mathrm{C} 3$ & $\sigma^{*}$ & 0.03197 & 1.19 & 1.33 & 0.036 \\
\hline & $\pi$ & 1.96013 & $\mathrm{C} 2-\mathrm{C} 3$ & $\pi^{*}$ & 0.03197 & 1.40 & 0.87 & 0.031 \\
\hline & & & C3-C4 & $\pi^{*}$ & 0.02368 & 1.29 & 0.85 & 0.030 \\
\hline \multirow[t]{4}{*}{ CR1-C1 } & $\sigma$ & 1.99891 & $\mathrm{C} 2-\mathrm{C} 3$ & $\sigma^{*}$ & 0.03197 & 0.95 & 10.63 & 0.091 \\
\hline & & & C2-C12 & $\sigma^{*}$ & 0.06646 & 0.88 & 10.42 & 0.087 \\
\hline & & & C5-C6 & $\sigma^{*}$ & 0.04829 & 1.01 & 10.60 & 0.093 \\
\hline & & & C6-Cl10 & $\sigma^{*}$ & 0.03231 & 0.56 & 10.26 & 0.068 \\
\hline \multirow[t]{3}{*}{ CR1-C12 } & $\sigma$ & 1.99917 & $\mathrm{C} 1-\mathrm{C} 2$ & $\sigma^{*}$ & 0.02368 & 0.63 & 10.78 & 0.074 \\
\hline & & & $\mathrm{C} 2-\mathrm{C} 3$ & $\sigma^{*}$ & 0.03197 & 0.60 & 10.80 & 0.072 \\
\hline & & & C12-O14 & $\sigma^{*}$ & 0.05805 & 0.65 & 10.51 & 0.075 \\
\hline \multirow[t]{2}{*}{ LP1-Cl10 } & $\sigma$ & 1.98882 & C1-C6 & $\sigma^{*}$ & 0.02745 & 1.97 & 1.17 & 0.043 \\
\hline & & & C5-C6 & $\sigma^{*}$ & 0.04829 & 1.62 & 1.17 & 0.039 \\
\hline \multirow[t]{4}{*}{ LP2-Cl10 } & $\sigma$ & 1.97091 & $\mathrm{C} 1-\mathrm{C} 2$ & $\sigma^{*}$ & 0.02368 & 0.63 & 0.83 & 0.021 \\
\hline & & & C1-C6 & $\sigma^{*}$ & 0.02745 & 4.02 & 0.83 & 0.051 \\
\hline & & & $\mathrm{C} 4-\mathrm{C} 5$ & $\sigma^{*}$ & 0.02745 & 0.62 & 0.83 & 0.020 \\
\hline & & & C5-C6 & $\sigma^{*}$ & 0.04829 & 5.30 & 0.82 & 0.059 \\
\hline LP3-C110 & $\sigma$ & 1.87827 & C1-C6 & $\sigma^{*}$ & 0.02745 & 13.93 & 0.31 & 0.062 \\
\hline \multirow[t]{2}{*}{ LP1-O16 } & $\sigma$ & 1.90400 & C3-C11 & $\sigma^{*}$ & 0.06646 & 3.07 & 1.09 & 0.052 \\
\hline & & & C11-O13 & $\sigma^{*}$ & 0.05805 & 0.52 & 1.01 & 0.021 \\
\hline C2-C12 & $\sigma$ & 1.97022 & Zn17-Cl19 & $\sigma^{*}$ & 0.16881 & 0.24 & 0.96 & 0.014 \\
\hline \multirow[t]{2}{*}{ C12-O15 } & $\sigma$ & 1.98331 & Zn17-Cl18 & $\sigma^{*}$ & 0.16881 & 0.23 & 1.11 & 0.015 \\
\hline & & & Zn17-Cl19 & $\sigma^{*}$ & 0.16881 & 0.12 & 1.11 & 0.011 \\
\hline CR1-C12 & $\sigma$ & 1.99917 & Zn17-Cl18 & $\sigma^{*}$ & 0.16881 & 0.10 & 10.56 & 0.030 \\
\hline LP1-O13 & $\sigma$ & 1.60745 & Zn17-Cl18 & $\sigma^{*}$ & 0.16881 & 0.10 & 1.09 & 0.010 \\
\hline LP5-Zn17 & $\sigma$ & 1.96913 & Zn17-Cl18 & $\sigma^{*}$ & 0.16881 & 6.74 & 0.88 & 0.071 \\
\hline LP1-C119 & $\sigma$ & 1.99182 & Zn17-Cl19 & $\sigma^{*}$ & 0.16881 & 5.25 & 0.82 & 0.061 \\
\hline
\end{tabular}

\section{CONCLUSIONS}

In this study, zinc and copper phthalic acid complexes with surface analysis and characterization were reported. These compounds may have the potential to be used as support materials to obtain effective catalysts or reducing agents. The structure of complex DCPAs was optimized by the B3LYP method using LanL2DZ basis sets. The energy gap between LUMO and HOMO was $1.7636 \mathrm{eV}$ in the $\mathrm{Cu}$ complex and $0.5238 \mathrm{eV}$ in the $\mathrm{Zn}$ complex. Global and local reactivity descriptors NBO values and MEP maps were defined using DFT method. $\mathrm{R}=0.97204$ for $\mathrm{Cu}$ and $\mathrm{R}=0.97929$ for $\mathrm{Zn}$ complex were found in linear fit studies. The theoretical and experimental FT-IR results were found to be consistent. 


\section{ACKNOWLEDGMENTS}

Authors thanks to Van Yuzuncu Y1l University Office of Scientific Research Projects for the financial support to his research laboratory.

\section{REFERENCES}

Cabir B, Yildiko, U, Ağirtaş, MS. (2019). Synthesis, DFT analysis, and electronic properties of new phthalocyanines bearing ETAEO substituents on peripheral position. Journal of Coordination Chemistry, 72(17): 2997-3011.

Cabir B, Yildiko, U, Ağırtaş, MS, Horoz, S. (2020). Computational DFT calculations, photovoltaic properties and synthesis of (2R, 3S)-2, 3, 4-trihydroxybutoxy substituted phthalocyanines. Inorganic and Nano-Metal Chemistry, 50 (9): 816-827.

Demir P, Akman, F. (2017). Molecular structure, spectroscopic characterization, HOMO and LUMO analysis of PU and PCL grafted onto PEMA-co-PHEMA with DFT quantum chemical calculations. Journal of Molecular Structure, 1134: 404-415.

Detsri E, Seeharaj, P. (2017). Colorimetric detection of glutathione based on phthalic acid assisted synthesis of silver nanoparticles. Colloids and Surfaces A: Physicochemical and Engineering Aspects, 533: 125-132.

El Bourakadi K, El Mehdi Mekhzoum, M, Boeré, RT, El Kacem Qais, A, Bouhfid, R. (2019). Synthesis, characterization and DFT studies of 6-bis(2-(thiazol-4-yl)-benzimidazol-1-yl)hexane hemihydrate crystal: Experimental and theoretical investigation. Journal of Molecular Structure, 1202: 127253.

Eşme A, Sağdınç, SG. (2017). Spectroscopic (FT-IR, FT-Raman, UV-Vis) analysis, conformational, HOMOLUMO, NBO and NLO calculations on monomeric and dimeric structures of 4-pyridazinecarboxylic acid by HF and DFT methods. Journal of Molecular Structure, 1147: 322-334.

Henglein A, Giersig, M. (1999). Formation of Colloidal Silver Nanoparticles: Capping Action of Citrate. The Journal of Physical Chemistry B, 103(44): 9533-9539.

Jayaprakash A, Arjunan, V, Jose, SP, Mohan, S. (2011). Vibrational and electronic investigations, thermodynamic parameters, HOMO and LUMO analysis on crotonaldehyde by ab initio and DFT methods. Spectrochimica Acta Part A: Molecular and Biomolecular Spectroscopy, 83(1): 411-419.

Khajehzadeh M, Moghadam, M. (2017). Molecular structure, FT IR, NMR, UV, NBO and HOMO-LUMO of 1(3-(dimethylamino)propyl)-1-(4-fluorophenyl)-1,3-dihydroisobenzofuran-5-carbonitrile by DFT/B3LYP and PBEPBE methods with LanL2DZ and $6-311++\mathrm{G}(\mathrm{d}, 2 \mathrm{p})$ basis sets. Spectrochimica Acta Part A: Molecular and Biomolecular Spectroscopy, 180: 51-66.

Kumar S, Radha, A, Kour, M, Kumar, R, Chouaih, A, Pandey, SK. (2019). DFT studies of disubstituted diphenyldithiophosphates of nickel(II): Structural and some spectral parameters. Journal of Molecular Structure, 1185: 212-218.

Liu H, Zhou, Y, Huang, H, Feng, Y. (2011). Phthalic acid modified TiO2 and enhanced photocatalytic reduction activity for $\mathrm{Cr}(\mathrm{VI})$ in aqueous solution. Desalination, 278(1): 434-437.

Liu L-C, Xing, F, Bai, Y, Shao, M, Li, M, Zhu, S. (2014). Synthesis, structure, thermal stability and luminescence of five 2D coordination polymers based on 4-(4-oxypyridinium-1-yl) phthalic acid and transition metal ions. Journal of Molecular Structure, 1067: 74-82.

Frisch M J. GWT, Schlegel HB, G. E. Scuseria, M. A. Robb, J. R. Cheeseman, G. Scalmani, V. Barone, G. A. Petersson, H. Nakatsuji, X. Li, M. Caricato, A. Marenich, J. Bloino, B. G. Janesko, R. Gomperts, B. Mennucci, H. P. Hratchian, J. V. Ortiz, A. F. Izmaylov, J. L. Sonnenberg, D. Williams-Young, F. Ding, F. Lipparini, F. Egidi, J. Goings, B. Peng, A. Petrone, T. Henderson, D. Ranasinghe, V. G. Zakrzewski, J. Gao, N. Rega, G. Zheng, W. Liang, M. Hada, M. Ehara, K. Toyota, R. Fukuda, J. Hasegawa, M. Ishida, T. Nakajima, Y. Honda, O. Kitao, H. Nakai, T. Vreven, K. Throssell, J. A. Montgomery, Jr., J. E. Peralta, F. Ogliaro, M. Bearpark, J. J. Heyd, E. Brothers, K. N. Kudin, V. N. Staroverov, T. Keith, R. Kobayashi, J. Normand, K. Raghavachari, A. Rendell, J. C. Burant, S. S. Iyengar, J. Tomasi, M. Cossi, J. M. Millam, M. Klene, C. Adamo, R. Cammi, J. W. Ochterski, R. L. Martin, K. Morokuma, O. Farkas, J. B. Foresman, and D. J. Fox. (2016). Gaussian 09, Revision A.02, Gaussian, Inc., Wallingford CT, . 
Mathammal R, Monisha, NR, Yasaswini, S, Krishnakumar, V. (2015). Molecular structure, vibrational analysis (FT-IR, FT-Raman), NMR, UV, NBO and HOMO-LUMO analysis of N,N-Diphenyl Formamide based on DFT calculations. Spectrochimica Acta Part A: Molecular and Biomolecular Spectroscopy, 139: 521532.

Mihçıokur Ö, Özpozan, T. (2017). Molecular structure, vibrational spectroscopic analysis (IR \& Raman), HOMOLUMO and NBO analysis of anti-cancer drug sunitinib using DFT method. Journal of Molecular Structure, 1149: 27-41.

Pandey M, Muthu, S, Nanje Gowda, NM. (2017). Quantum mechanical and spectroscopic (FT-IR, FTRaman,1H,13C NMR, UV-Vis) studies, NBO, NLO, HOMO, LUMO and Fukui function analysis of 5Methoxy-1H-benzo[d]imidazole-2(3H)-thione by DFT studies. Journal of Molecular Structure, 1130: 511-521.

Prabhaharan M, Prabakaran, AR, Gunasekaran, S, Srinivasan, S. (2015). DFT studies on vibrational spectra, HOMO-LUMO, NBO and thermodynamic function analysis of cyanuric fluoride. Spectrochimica Acta Part A: Molecular and Biomolecular Spectroscopy, 136: 494-503.

Priya MK, Revathi, BK, Renuka, V, Sathya, S, Asirvatham, PS. (2019). Molecular Structure, Spectroscopic (FTIR, FT-Raman, 13C and 1H NMR) Analysis, HOMO-LUMO Energies, Mulliken, MEP and Thermal Properties of New Chalcone Derivative by DFT Calculation. Materials Today: Proceedings, 8: 37-46.

Rawat KA, Singhal, RK, Kailasa, SK. (2017). One-pot synthesis of silver nanoparticles using folic acid as a reagent for colorimetric and fluorimetric detections of 6-mercaptopurine at nanomolar concentration. Sensors and Actuators B: Chemical, 249: 30-38.

Rocha M, Di Santo, A, Arias, JM, Gil, DM, Altabef, AB. (2015). Ab-initio and DFT calculations on molecular structure, NBO, HOMO-LUMO study and a new vibrational analysis of 4-(Dimethylamino) Benzaldehyde. Spectrochimica Acta Part A: Molecular and Biomolecular Spectroscopy, 136: 635-643.

Saravanan RR, Seshadri, S, Gunasekaran, S, Mendoza-Meroño, R, Garcia-Granda, S. (2014). Crystallographic, experimental (FT-IR and FT-RS) and theoretical (DFT) investigation, UV-Vis, MEP, HOMO-LUMO and NBO/NLMO of (E)-1-[1-(4-Chlorophenyl)ethylidene]thiosemicarbazide. Spectrochimica Acta Part A: Molecular and Biomolecular Spectroscopy, 121: 268-275.

Solğun DG, Keskin, MS, Yıldıko, Ü, Ağırtaş, MS. (2020). DFT analysis and electronic properties, and synthesis of tetra (9-phenyl-9H-xanthen-9-yl) oxy peripheral-substituted zinc phthalocyanine. Chemical Papers, 74: 2389-2401.

Srivastava AK, Pandey, AK, Jain, S, Misra, N. (2015). FT-IR spectroscopy, intra-molecular C-H‥O interactions, HOMO, LUMO, MESP analysis and biological activity of two natural products, triclisine and rufescine: DFT and QTAIM approaches. Spectrochimica Acta Part A: Molecular and Biomolecular Spectroscopy, 136, 682-689.

Vennila P, Govindaraju, M, Venkatesh, G, Kamal, C. (2016). Molecular structure, vibrational spectral assignments (FT-IR and FT-RAMAN), NMR, NBO, HOMO-LUMO and NLO properties of Omethoxybenzaldehyde based on DFT calculations. Journal of Molecular Structure, 1111: 151-156. 